\title{
MEAN SEA SURFACE (MSS) MODEL DETERMINATION FOR MALAYSIAN SEAS USING MULTI-MISSION SATELLITE ALTIMETER
}

\author{
N A Z Yahaya ${ }^{1}$, T A Musa ${ }^{1}$, K M Omar ${ }^{1}$, A H M Din ${ }^{1,2}$, A H Omar ${ }^{1}$, A Tugi ${ }^{1}$, N M Yazid ${ }^{1}$, N M Abdullah ${ }^{1}$ and M I A Wahab ${ }^{3}$ \\ ${ }^{1}$ Geomatic Innovation Research Group (GnG), Faculty of Geoinformation and Real Estate, Universiti Teknologi \\ Malaysia, 81310 Johor Bahru, Johor, Malaysia. \\ ${ }^{2}$ Geoscience and Digital Earth Centre (INSTEG), Universiti Teknologi Malaysia, 81310 Johor Bahru, Johor, Malaysia. \\ ${ }^{3}$ Quality Engineering Department, Universiti Kuala Lumpur, Malaysian Institute of Industrial Technology, Persiaran \\ Sinaran Ilmu, 81750 Bandar Seri Alam, Johor Bahru, Johor, Malaysia, \\ *nooranim@utm.my or anim.zanariah@gmail.com
}

KEY WORDS: Sea Surface Height, Mean Sea Surface, RADS, Satellite Altimeter

\begin{abstract}
:
The advancement of satellite altimeter technology has generated many evolutions to oceanographic and geophysical studies. A multimission satellite altimeter consists with TOPEX, Jason-1 and Jason-2, ERS-2, Envisat-1, CryoSat-2 and Saral are extracted in this study and has been processed using Radar Altimeter Database System (RADS) for the period of January 2005 to December 2015 to produce the sea surface height (hereinafter referred to SSH). The monthly climatology data from SSH is generated and averaged to understand the variation of SSH during monsoon season. Then, SSH data are required to determine the localised and new mean sea surface (MSS). The differences between Localised MSS and DTU13 MSS Global Model is plotted with root mean square error value is 2.217 metres. The localised MSS is important towards several applications for instance, as a reference for sea level variation, bathymetry prediction and derivation of mean dynamic topography.
\end{abstract}

\section{RESEARCH BACKGROUND}

\subsection{Introduction}

Over the past years, the progression of satellite altimeter has been tremendously improved. Previously, the study of ocean variability is limited to certain ocean area and only came from tidal gauges, buoys and ships. With the presence of satellite altimeter, information such as the height of the oceans over nearly $60 \%$ of the earth's surface are able to be obtained.

Majumdar and Bhattacharyya (2005) stated that satellite altimeter measures the instantaneous sea surface height at the nadir with good precision. A pulse-limited radar is used to measure the altitude of the satellite above the closest sea surface point which, to a first approximation (is a measure of) geoid height or gravitational potential as shown in Figure 1. The difference between the satellite's height above the ellipsoid and above the Earth's surface gives the height of the topography relative to the reference ellipsoid. The precision over land areas is poorer than oceans, but over smooth land features like desserts and inland water bodies, an accuracy of better than a meter is achievable (Lowrie, 2007).

According to Peacook and Laxon (2004), the satellite altimeter has been used in the measurement of the time invariant component of sea surface height or mean sea surface, on a global basis. Furthermore, Jin et al. (2016) stated the satellite altimetry has greatly improved the spatial and temporal resolution of sea surface height (SSH) observations since the first satellite Geo-3 is launched in the 1970s. A series of global and regional mean sea surface (MSS) models has been established, however, only two institutions are still publishing MSS models (the Centre National d'Etudes Spatiales (CNES) and the Space Research Centre of the Technical University of Denmark (DTU)). The Mean Sea Surface (MSS) is an essential and important product of satellite altimeter for supporting to oceanographic and geophysical studies (Hwang et al., 2002).

It is the time-averaged physical height of the ocean's surface. In principle, a complete separation of the oceans means and a variable part requires uninterrupted infinite sampling in both time and space (Andersen and Knudsen, 2009). For some applications in physical oceanography, the MSS is generally used as a reference field for altimeter missions (Schaeffer et al., 2012). The determination of the MSS for Malaysian Seas integrates several applications namely:
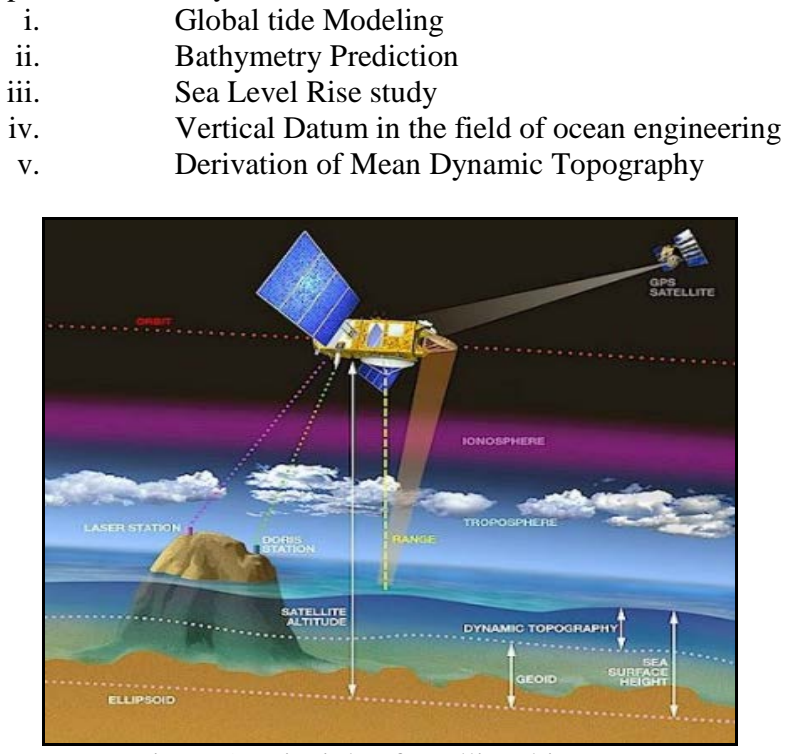

Figure 1. Principle of satellite altimetry (Fu and Cazenave, 2001) 
This study aims to determine the MSS for Malaysian Seas. First the data and the methodology used are described, in particular the method used to process the SSH. This step is crucial for processing the altimetry data because it is intended for defining the average content of the SSH that will serve later as main data. Other parts of this study are also dedicated to mapping the monthly climatological data from the sea surface height data derivation for certain years. The mapping of SSH variability during Malaysia's seasonal monsoons are presented. Finally, the comparison of the new localised MSS model with global model the quality of this new MSS by various validations is defined.

\section{RESEARCH APPROACH}

\subsection{Study Area}

In order to meet the requirements of the study, the selected study area is chosen includes four Malaysian Seas; the Straits of Malacca in Peninsular Malaysia, South China Sea and Sabah seas (the Celebes Sea and Sulu Sea). The geographical data boundary used for all data extraction is between $0^{\circ} \leq$ Latitude $\leq$ $14^{\circ} \mathrm{N}$ and $95^{\circ} \mathrm{E} \leq$ Longitude $\leq 126^{\circ} \mathrm{E}$.

\subsection{Sea Surface Height (SSH) Computation from Satellite Altimeter}

Satellite altimeter transmits microwave radiation to the sea surface and the signal is reflected back to the altimeter (Andersen and Scharroo, 2011; Fu et. al., 1988). The range, $R_{\text {Obs }}$ is measured from the travel time taken by the signal to propagate from the transmitter to the sea surface and back to the receiver on-board. The instantaneous height of the sea surface, $h_{\text {SSH }}$ at particular time is relative to a reference ellipsoid while the altitude, $H_{\text {SALT }}$ of the altimeter above the corresponding reference ellipsoid is given by an independent tracking system (Din and Omar, 2009).

The sea surface height, $h_{S S H}$ can in its simplest form be described according to the following expression, instantaneous sea surface height,

$$
h_{\text {SSH }}=H_{\text {SALT }}-R_{\text {ObS }}
$$

where $h_{S S H}=$ the instantaneous height of sea surface height (SSH) above the reference ellipsoid

$H_{\text {SALT }}=$ the altitude of the altimeter above the corresponding reference ellipsoid

$R_{\text {Obs }}=$ the travel time taken from the transmitter to the sea surface and back to the receiver on-board

However, the satellite altimeter measures the range to the sea surface and the data initially corrected for various range corrections. These range corrections are performed to model the behaviour of the speed of the radar through the atmosphere and the interaction with the sea surface through the sea state correction (Andersen, 2012). Fu and Cazenave (2001) stated that the height of the spacecraft is determined relative to the reference ellipsoid through Precise Orbit Determination and Global Positioning System (GPS) on-board. Combining the knowledge of the height of the spacecraft with the corrected range gives the sea surface height relative to the reference ellipsoid. For this study, all atmospheric, instrument and geophysical corrections is included (see Table 1) to obtain SSH;

$$
\begin{aligned}
h_{S S H}= & H_{S A I T}-R_{\text {Obs }}-\Delta h_{\text {ion }}-\Delta h_{\text {dry }}-\Delta h_{\text {wet }} \\
& -\Delta h_{S S B}-h_{I B}-h_{\text {load }}-h_{\text {golid earth }} \\
& -h_{\text {pole }}-h_{\text {ocean tide }}
\end{aligned}
$$

where $h_{S S H}=$ the instantaneous height of sea surface height (SSH) above the reference ellipsoid

$R_{\text {obs }}=$ the travel time taken from the transmitter to the sea surface and back to the receiver onboard

$H_{\text {SALT }}$ = the altitude of the altimeter above the corresponding reference ellipsoid

$\Delta h_{\text {ion }}=$ ionospheric correction

$\Delta h_{d r y}=$ dry tropospheric correction (Oxygen and Nitrogen)

$\Delta h_{\text {wat }}=$ wet tropospheric correction (water vapour)

$\Delta h_{\text {SSB }}=$ sea state bias correction

$h_{l B}=$ inverse barometric effect

$h_{\text {lood }}=$ load tide effect

$h_{\text {solid earth }}=$ solid earth tide effect

$h_{\text {pole }}=$ pole tide effect

$h_{\text {ocentidg }}=$ ocean tide effect

\begin{tabular}{|l|l|}
\hline Atmospheric Corrections & \multicolumn{1}{|c|}{ Model/Sensor } \\
\hline Ionosphere & $\begin{array}{l}\text { Smoothed dual-frequency } \\
\text { value }\end{array}$ \\
\hline Dry Troposphere & $\begin{array}{l}\text { European Centre for } \\
\text { Medium-Range Weather } \\
\text { Forecasts (ECMWF) }\end{array}$ \\
\hline Wet Troposphere & Radiometer \\
\hline \multicolumn{2}{|c|}{ Signal-Surface Interaction } \\
\hline Sea State Bias & CLS non-parametric model \\
\hline \multicolumn{2}{|c|}{ Geophysical Correction } \\
\hline Inverse Barometer & MOG2D model \\
\hline Load Tides & GOT4.7/4.8 \\
\hline Solid Earth Tides & Solid Earth Tides \\
\hline Pole Tides & Pole Tides \\
\hline Ocean Tides & GOT4.8 \\
\hline Geoid & None \\
\hline \multicolumn{2}{|c|}{ References } \\
\hline Ellipsoid & WGS84 \\
\hline \multicolumn{2}{|c|}{ Tist of corrections applied } \\
\hline
\end{tabular}

2.2.1 Satellite Missions: In this study, 11 years (2005-2015) satellite altimeter (ERS-2, Envisat-1, CryoSat-2 and Saral) data have been used to obtain the sea surface height for Malaysian Seas. While the TOPEX-class satellites (TOPEX, Jason-1 and Jason-2) fix as a reference to the other-class satellites and are adjusted simultaneously throughout the processing. Table 2 summaries the details of the satellite altimeter and its status.

2.2.2 Processing Flows: Anderson (2012) highlighted that altimetry data are accessible and well-distributed through agencies, like the European Organisation for the Exploitation of Meteorological Satellites (EUMETSAT), AVISO, the Physical Oceanography Distributed Active Archive Center (PO.DAAC) and the National Oceanic and Atmospheric Administration (NOAA). In addition to these operational data centres, the Radar Altimeter Database System (RADS) is a joint effort by the Department for Earth Observation and Space Systems (DEOS), Delft University of Technology and the NOAA Laboratory for Satellite Altimetry in establishing a harmonised, 
The International Archives of the Photogrammetry, Remote Sensing and Spatial Information Sciences, Volume XLII-4/W1, 2016 International Conference on Geomatic and Geospatial Technology (GGT) 2016, 3-5 October 2016, Kuala Lumpur, Malaysia

validated and cross-calibrated sea level database from all altimeter missions.

\begin{tabular}{|c|c|c|c|}
\hline Satellite & Phase & Period & Cycles \\
\hline TOPEX & B & Oct 2005 - Dec 2005 & $369-481$ \\
\hline JASON-1 & A & Jan 2005 - Jan 2009 & $001-260$ \\
& B & Feb 2009 - Mar 2012 & $262-374$ \\
& C & May 2012 - Jun 2013 & $382-425$ \\
\hline JASON-2 & A & Jul 2008 - Dec 2015 & $000-297$ \\
\hline ENVISAT- & B & Jan 2005 - Oct 2010 & $006-094$ \\
1 & C & Oct 2010 - Apr 2012 & $095-113$ \\
\hline CRYOSAT- & A & July 2010 - Dec 2015 & $004-082$ \\
$\mathbf{2}$ & & & \\
\hline & & & \\
\hline SARAL & A & Mar 2013 - Dec 2015 & $001-035$ \\
& B & Jul 2016 - Dec 2015 & $036-036$ \\
\hline
\end{tabular}

Table 2. Satellite Altimetry Data Processed in RADS

In the RADS, certain shell script files are created and used in accessing and analysing desired results that suit to the requirement of this study. Firstly, a file called "getraw.nml" is created to enable the user to define the geographical region of interest in latitude and longitude, including other parameters. Then, the crossover adjustment is performed by applying altimeter corrections and removing bias in RADS processing. Schrama (1989) suggested since the TOPEX and JASON satellites can give better accuracy compares to other satellites, the sea surface heights (SSH) from different satellite missions need to be adjusted to a "standard" surface.

The time frame covered by the individual crossovers is pegged at 18 days to increase the likelihood of capturing all available real oceanic signals and sea level trends (Trisirisatayawong et al., 2011). A distance-weighted gridding is applied to obtain useful values for points situated between footprints. The Gaussian distribution, $F_{\mathrm{V}}(r)$ is relied on for the weighting function (Singh et al., 2004):

$$
F_{W V}(r)=e^{-\frac{F^{2}}{s^{2}}}
$$

where sigma, $\sigma=$ weight given to a value at a normal point with location of a distance from the grid point

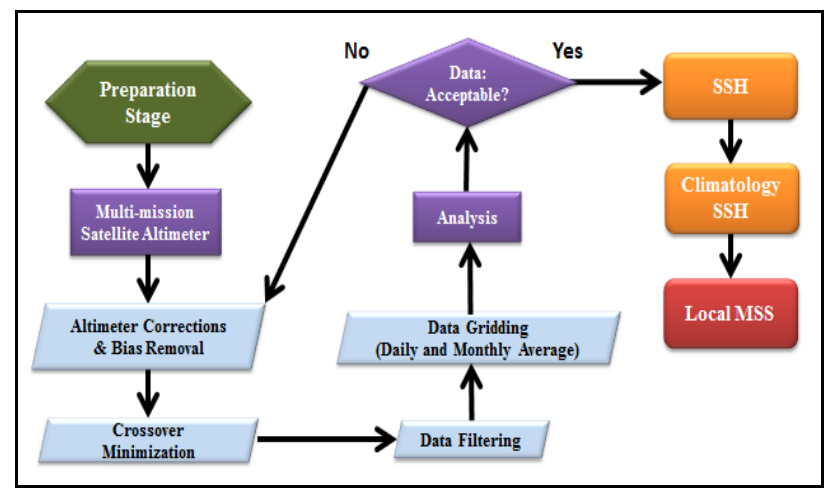

Figure 2. Altimeter Data Processing Flows used in RADS (Modified from Din, et al. (2014))

The sigma 1.5 weighting function is used to filter and grid the data to sea surface height bins using the Gaussian weighting function. A square mesh with block size of $0.25^{\circ}$ (spatial) and an 9 days cut-off (temporal) is factored into the gridding step that used for spatial and temporal weighting on SSH anomaly.

\subsection{Mean Sea Surface (MSS) Model Determination}

In order to generate localised Mean Sea Surface (MSS) Model for Malaysian seas, the climatology data of the SSH for 11 years has been spatially averaged.

$$
\text { MSS }_{\text {local }}=\frac{1}{n} \sum_{i=1}^{n} x i
$$

where MSS $_{\text {local }}=$ The localised Mean Sea Surface Model $x i=$ climatological data of sea surface height $n=$ number of samples (point) $i=$ sea surface height value

The high-resolution MSS model is derived by merging several years (11 years) of repeated observations from selected satellite altimeters and gridded Localised MSS Model for Malaysian Sea, afterwards has to be compared to global MSS. A global model of mean sea surface used for this study is DTU13 Global Mean Sea Surface Model which has been extracted from RADS (Figure 3). Other than that, the equation for comparing both models are followed;

$$
\triangle \mathrm{MSS}=\mathrm{MSS}^{\text {Local }}-\mathrm{MSS}^{\mathrm{DTU} 13}
$$

where $\Delta$ MSS = Difference value of compared MSS MSS $^{\text {Local }}=$ Value of the Localised MSS Model MSS $^{\text {DTU13 }}=$ Value of the DTU13 Global MSS Model

RMSE $=\sqrt{\sum_{i=0}^{n} \frac{(\Delta M S S)^{2}}{n}}$

Where AMSS = Difference value of comparing MSS $\mathrm{n}=$ number of points

$i=$ sea surface height value

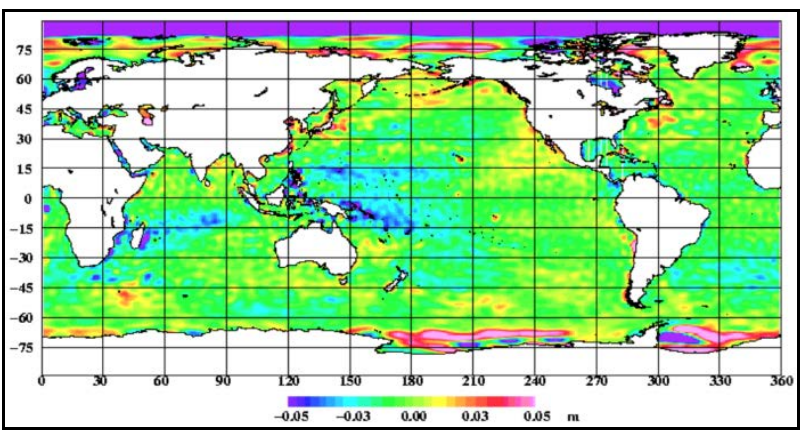

Figure 3. DTU13 Global Mean Sea Surface Model (Anderson et al.,2015)

\section{RESULT AND DISCUSSION}

\subsection{Monthly Sea Surface Height Climatology Variation For 11 Years}

Monthly climatological data contain the sea surface height (SSH) data every month for the chosen years. The altimeter data from the years of 2005 to 2015 are analysed below to provide an independent verification of climatological descriptions. However the climatology data from SSH has been subtracted from Localised Mean Sea Surface (new model) to provide the anomaly as mapping shown because of the changes from SSH is slightly small and does not appear to be significant when it been 
plotted. Figure 4 shows a SSH anomaly for the month of January - June (Figure 5 for July - December), from a new SSH climatology derived exclusively from the 11-year dataset. It can be seen that there are some areas of the SSH anomaly where the quantity or quality of data are varies for each month.

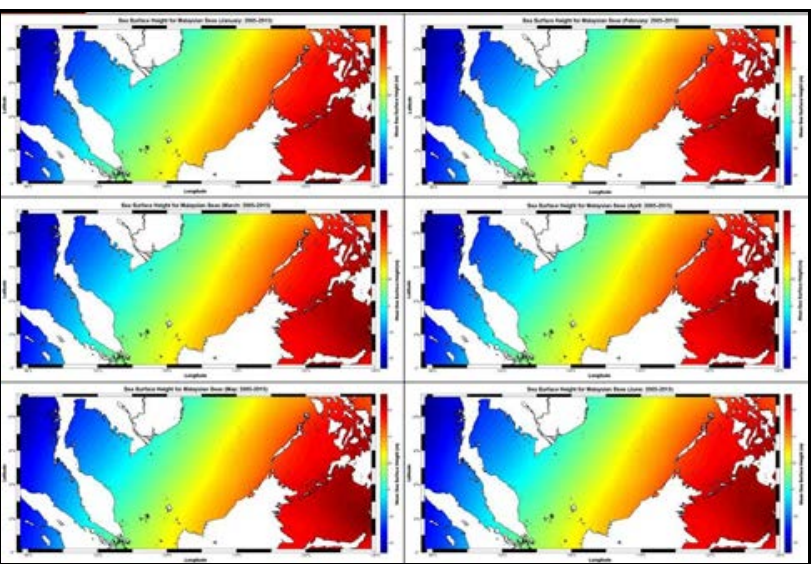

Figure 4. SSH Jan to June in 11 years (2005- 2015)

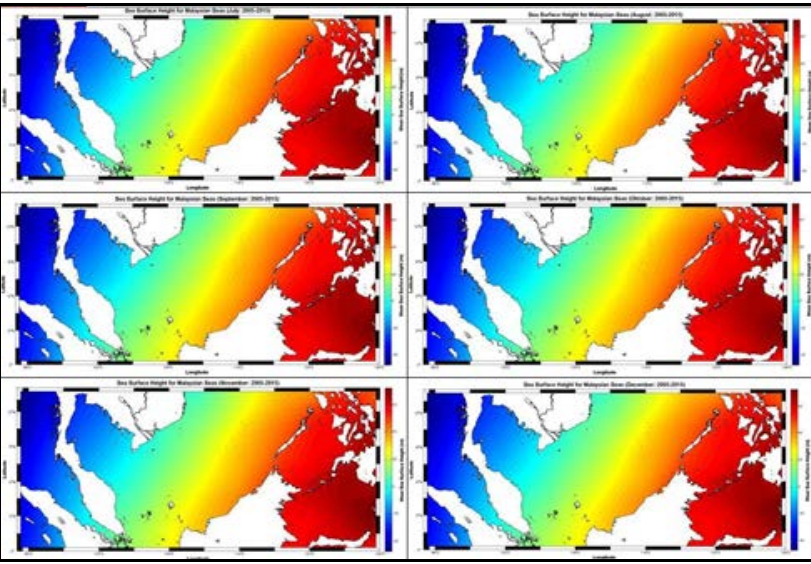

Figure 5. SSH July to August in 11 years (2005- 2015)

\subsection{Sea Surface Height Variability}

After generating the SSH profiles of climatology data, the same data is averaged to indicate the variation of SSH during Malaysia Seasonal Monsoon. Malaysia faces two significant monsoon seasons, the Southwest Monsoon from May to August, and the Northeast Monsoon from November to February with two Inter Monsoon transitions between the two monsoons, from March to April for the first transition and from September to October for the second transition (MMD, 2016). Figure 6 and Figure 7 illustrated that variation of SSH anomaly during the $1^{\text {st }}$ and $2^{\text {nd }}$ Inter monsoon, which, are appeared to be calm and not much increase in the height of the sea surface.

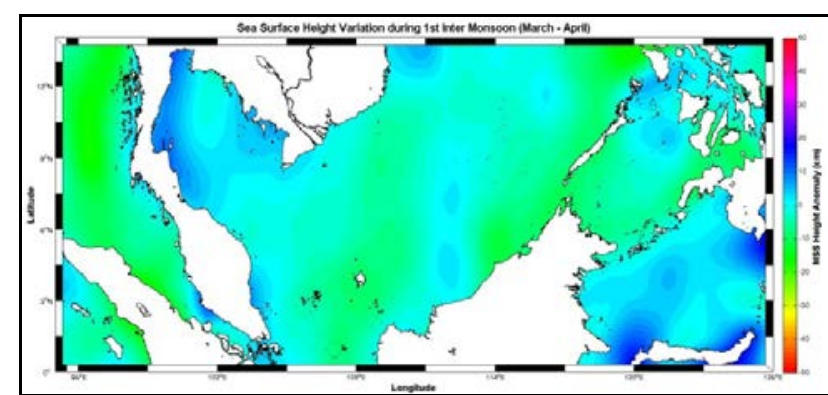

Figure 6. The Sea Surface Height Variation during $1^{\text {st }}$ Inter Monsoon

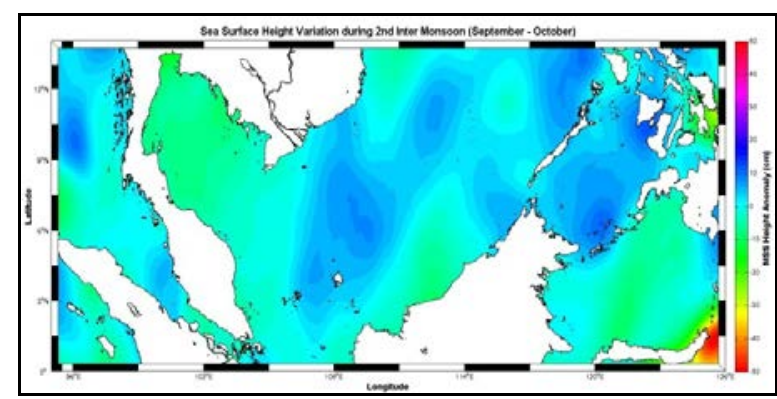

Figure 7. The Sea Surface Height Variation during $2^{\text {nd }}$ Inter Monsoon

On the other hand, the Southwest Monsoon variation in Figure 8 reveals a slightly increasing in the height of the sea surface at the Straits of Malacca area since the monsoon season produced an average rainfall throughout the 4 months (Sang et al., 2015a).

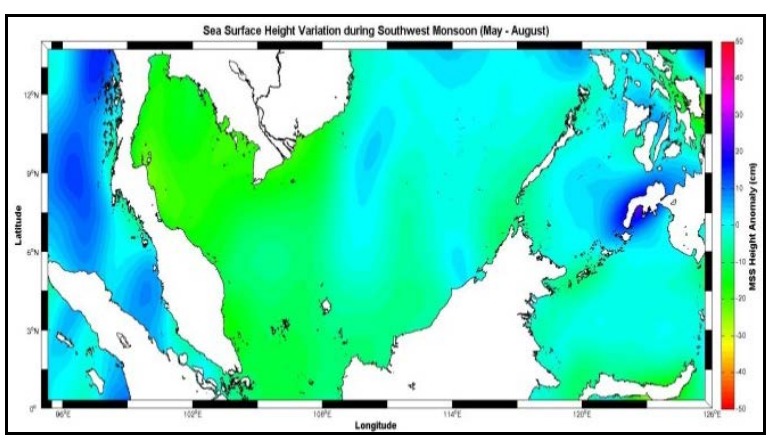

Figure 8. The Sea Surface Height Variation during Southwest Monsoon

However, the pattern intensified during the Northeast Monsoon where the variation of sea surface height at its most highest among other season at South China Sea (Figure 9). It is due to the characteristics of the Northeast Monsoon which brings heavy rainfall, particularly in the east coast states of Peninsular Malaysia and western Sarawak (Sang et al., 2015b).

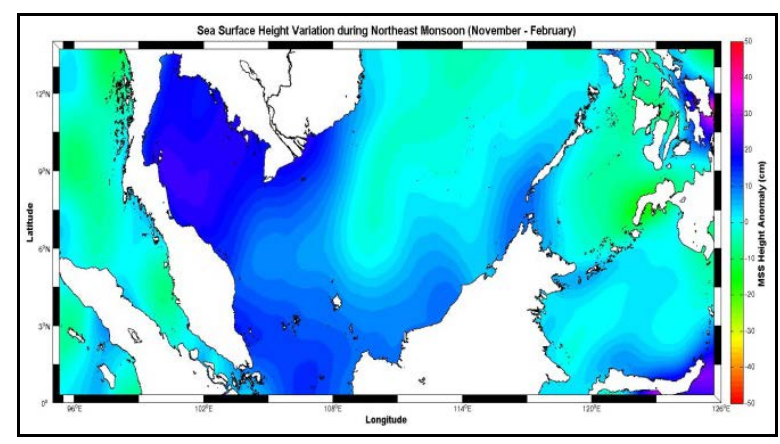

Figure 9. The Sea Surface Height Variation during Northeast Monsoon

\subsection{Localised MSS Model for Malaysian Seas}

The mean sea surface (MSS) relates to the sum of mean geoid and mean ocean dynamic topography. However, for this study, the MSS is geometrically obtained from the difference between the SSH and the sea level anomaly. Figure 10 presents the new MSS model derived from satellite altimeter data acquired from TOPEX, Jasons-1\&2, ERS-2, Envisat, Cryosat-2 and Saral missions covering the Malaysian Seas. 


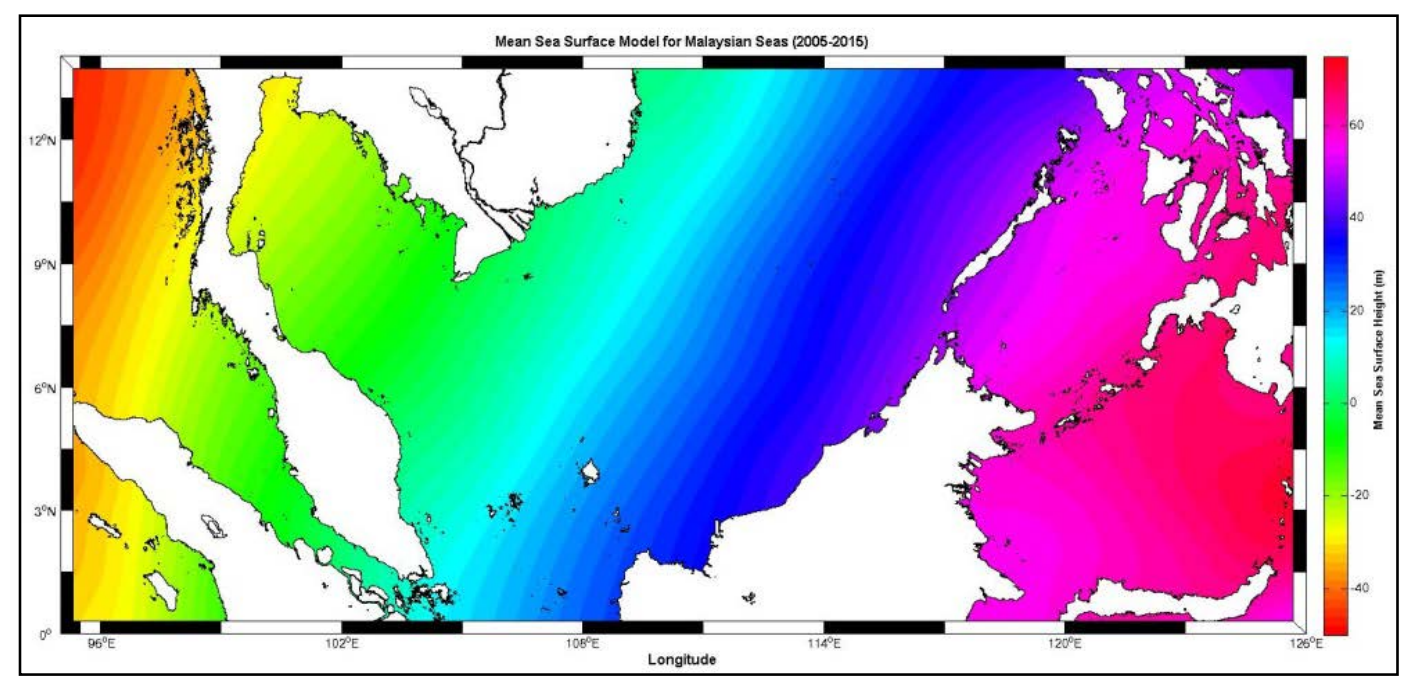

Figure 10. Localise Mean Sea Surface for Malaysian Sea

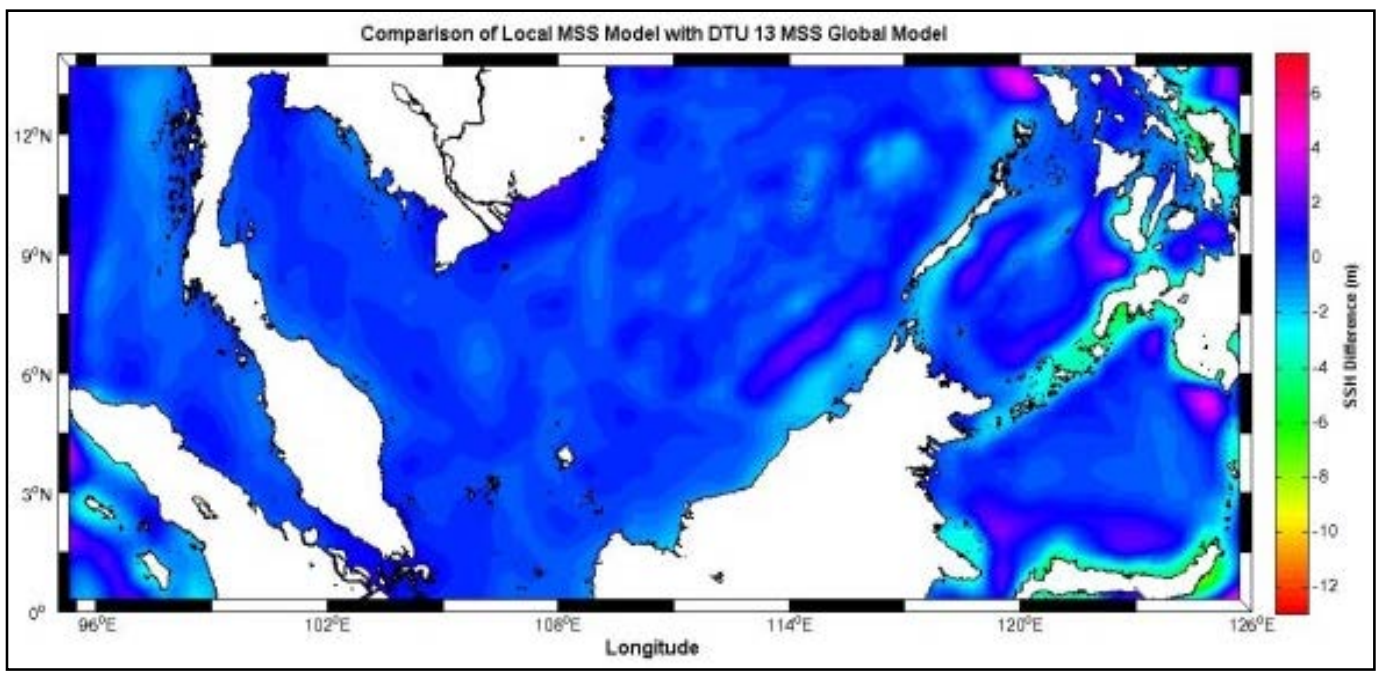

Figure 11. Difference between the DTU13 Global MSS Model and Localised MSS Model in Malaysian Seas displayed on a $0.25^{\circ}$ resolution grid.

From Figure 10, it can be comprehended that the mean sea surface increases eastwards from West Malaysia (Peninsular) towards West Malaysia (Sabah and Sarawak).

\subsection{Comparison of New Localised MSS Model with DTU13 MSS Global Model}

Data from DTU13 Global MSS Model is utilised to evaluate the constructed new and localised MSS Model. For this MSS Model for Malaysian Seas, the difference between mean sea surface heights (local) and global model (DTU13) have to be computed. Figure 11 signified the difference between Localised MSS Model and DTU13 MSS Global Model. Meanwhile, Table 3 represents a statistical analysis of the difference between DTU13 Global MSS Model and Localised MSS Model .

\begin{tabular}{llllll}
\hline $\begin{array}{l}\text { MIN } \\
(\mathbf{m})\end{array}$ & $\begin{array}{l}\text { MAX } \\
(\mathbf{m})\end{array}$ & $\begin{array}{l}\text { AVERAGE } \\
(\mathbf{m})\end{array}$ & $\begin{array}{l}\text { SUM } \\
(\mathbf{m})\end{array}$ & $\begin{array}{l}\text { RMSE } \\
(\mathbf{m})\end{array}$ \\
\hline AMSS & -13.426 & 7.443 & -0.30004 & -2137.8 & 2.217 \\
\hline
\end{tabular}

Table 3. Statistic of the difference between

DTU13 Global MSS Model and Localised MSS Model

\section{CONCLUSION}

In this paper, multi-mission satellite altimeter observations are combined to produce the monthly climatological SSH data. From the SSH data, the variation of sea surface is generated and mapped during the monsoon season. Moreover, the SSH data are required to establish a localised mean sea surface for Malaysian Seas using the mean of gridded SSH spanning the 11 years data, between 2005 and 2015. The MSS is an important reference for sea level variation. Besides, MSS is capable to integrate other oceanographic and geophysical studies, such as for global tide modeling, bathymetry prediction and vertical datum determination in the field of ocean engineering.

\section{ACKNOWLEDGEMENTS}

The authors would like to thank the TUDelft NOAA and Altimetrics LLC for providing altimetry data. Special thanks are due to Universiti Teknologi Malaysia (UTM) and the Ministry of Education (MOE) Malaysia for the Research University 
Grant Scheme (GUP) Vot No. $12 \mathrm{H} 99$ given to complete this research project.

\section{REFERENCES}

Andersen, O. B., 2012. Marine Gravity and Geoid from Satellite Altimetry. Lecture Notes in Earth System Sciences, 110, 401-451.

Andersen, B. and Knudsen, P., 2009. DNSC08 mean sea surface and mean dynamic topography models. Journal of Geophysical Research (Oceans),114 (C11).

Andersen, O. B., Knudsen, P., Stenseng, L., 2015. The DTU13 MSS (Mean Sea Surface) and MDT (Mean Dynamic Topography) from 20 Years of Satellite Altimetry. Part of the series International Association of Geodesy Symposia, (1-10).

Andersen, O. B. and Scharroo, R., 2011. Range and geophysical corrections in coastal regions: and implications for mean sea surface determination. Coastal Altimetry, 103-146. Springer.

Din, A. H M. and Omar, K. M., 2009. Sea Level Change in the Malaysian Seas from Multi-Satellite Altimeter Data. Faculty of Geoinformation Science and Engineering. Universiti Teknologi Malaysia.

Din, A. H M., Ses, S., Omar, K. M., Naeije, M., Yaakob, O., Pa'suya, M. F., 2014. Derivation of Sea Level Anomaly Based on the Best Range and Geophysical Corrections for Malaysian Seas using Radar Altimeter Database System (RADS). Jurnal Teknologi (Sciences \& Engineering), 71:4 (83-91).

Fu, L. L., Chelton, D.B. and Zlotnicki, V., 1988. Satellite altimetry: Observing ocean variability from space. Oceanography, 1(2):4,

http://dx.doi.org/10.5670/oceanog.1988.01.

Fu, L.L. and Cazenave, A., 2000. Satellite altimetry and earth sciences: a handbook of techniques and applications. (Vol. 69) Academic Press.

Fu, L.L. and Cazenave A., 2001. Altimetry and Earth Science, A Handbook of Techniques and Applications. International Geophysics Series, 69. Academic Press, London.

Hwang, C., Hsu, H.Y. and Jang, R.J., 2002. Global mean sea surface and marine gravity anomaly from multi-satellite altimetry: applications of deflection-geoid and inverse Vening Meinesz formulae. Journal of Geodesy, 76, (407-418)

Jin, T., Li, J., Jiang, W., 2016. The global mean sea surface model WHU2013, Geodesy and Geodynamics, 7 (3), 200-209.

Lowrie, W., 2007. Fundamentals of Geophysics, Cambridge University Press, New York, UK.

Majumdar, T.J. and Bhattacharyya, R., 2005. Bathymetry prediction model from high-resolution satellite gravity as applied over a part of the eastern Indian offshore. Current Science, 89 (10), 1754-1758.

Malaysian Meteorological Department, 2016. Retrieved on 20 July 2016, http://www.met.gov.my/web/metmalaysia/climate/generalinfor mation/malaysia
Naeije, M., Schrama, E. and Scharroo, R., 2000. The radar altimeter database system project rads. Proceedings of the 2000 Geoscience and Remote Sensing Symposium, 2000. Proceedings. IGARSS 2000. IEEE 2000 International: IEEE, 487-490.

Neil R., Peacock, N. R. and Laxon, S. W., 2004. Sea surface height determination in the Arctic Ocean from ERS altimetry. Journal of Geophysical Research, 109 (C7). London, UK.

Schaeffer, P. ,Faug’Ere, Y. , Legeais, J. F., Ollivier, A. , Guinle, T. And Picot, N., 2012. The Cnes Cls11 Globalmean Sea Surface Computed From 16 Years Of Satellite Altimeter Data. Marine Geodesy, 35(S1):3-19, 2012. Taylor \& Francis Group, LLC

Scharroo RE, Leuliette W, Lillibridge JL, Byrne D, Naeije MC, Mitchum GT., 2012. RADS: consistent multi-mission products. In: Proc. of the symposium on 20 years of progress in radar altimetry, Venice, Eur. Space Agency Spec. Publ., ESA SP-710; 2013. p. 4.

Schrama, E., 1989. The role of orbit errors in processing of satellite altimeter data. Geodesy, 33 : 167. Netherlands Geodetic Commission.

Singh, M., Mandal, M. and Basu, A., 2004. Robust KLT tracking with Gaussian and Laplacian of Gaussian weighting functions. Proceedings of the 2004 null: IEEE, 661-664.

Trisirisatayawong, I., Naeije, M., Simons, W. and FenoglioMarc, L., 2011. Sea Level Change in the Gulf of Thailand from GPS Corrected Tide Gauge Data and Multi-Satellite Altimetry. Global Planetary Change, 76: 137-151.

Yip Weng Sang, Fadila Jasmin binti Fakaruddin, Fatimah Zahrah binti Salleh, Mat Kamaruzaman bin Mat Adam, Nursalleh K Chang, Fariza binti Yunus and Muhammand Helmi bin Abdullah . 2015(a). Characteristics of the 2015 Southwest Monsoon in Malaysia. Malaysian Meteorological Department. 2016. Retrieved on 15 July 2016,

http://www.met.gov.my/web/metmalaysia/analisisteknikal/document/233757/SW2015.

Yip Weng Sang, Diong Jeong Yik, Nursalleh K. Chang, Mat Kamaruzaman Mat Adam, Fadila Jasmin Fakaruddin, Fatimah Zaharah Saleh, Dr. Fariza Yunus and Muhammad Helmi Abdullah 2015(b). Analysis of the Northeast Monsoon 2014/2015. Malaysian Meteorological Department. 2016. Retrieved on 15 July 2016.

http://www.met.gov.my/ms/web/metmalaysia/analisisteknikal/document/233757/NE 